\title{
Pengaruh Independensi, Akuntabilitas, Time pressure dan Due Professional Care Terhadap Kualitas Audit pada Inspektorat Musi Banyuasin Sekayu
}

\author{
Pipit Fitri Rahayu $^{\mathbf{1}}$ dan Crystha Armereo ${ }^{2}$ \\ 1-2 Jurusan Akuntansi, Universitas Tridinanti Palembang \\ Email: pipitfitrirahayu@univ-tridinantiac.id \\ Email: crystha armereo@univ-tridinanti.ac.id
}

\begin{abstract}
The purpose of this study are to determine the independence, accountability, time pressure and due professional care on the audit quality of the Inspektorat Musi Banyuasin in Sekayu. While the population used in this study were all auditors in the Inspectorate of Musi Banyuasin Sekayu to 67 people. The sample that used is 67 people using a census is all the populations sampled. Technique to analyze data are multiple regression analysis with SPSS 20 software tools. The results of the study partially indicate that: (1) independence has a negative effect and not significant towords the audit qualitry of Inspectorate of Musi Banyuasin Sekayu, (2) accountability has a positive effect and not significant towords the audit qualitry of Inspectorate of Musi Banyuasin Sekayu, (3) time pressure has a positive effect and significant towords the audit qualitry of Inspectorate of Musi Banyuasin Sekayu, and (4) due professional care has a positive effect and not significant towords the audit qualitry of Inspectorate of Musi Banyuasin Sekayu. And the results of the simultaneous testing also show that independence, accountability, time pressure and due professional care have a positive and significant effect on the audit quality of Inspectorate Musi Banyuasin Sekayu.
\end{abstract}

Keywords: Independence, Accountability, Time Pressure, Due Professional Care, and Audit Quality.

\begin{abstract}
Abstrak
Tujuan dari penelitian ini adalah untuk mengetahui pengaruh independensi, akuntabilitas, time pressure, dan due professional care terhadap kualitas audit pada Inspektorat Musi Banyuasin Sekayu. Sedangkan populasi yang digunakan dalam penelitian ini adalah seluruh auditor yang ada di Inspektorat Musi banyuasin Sekayu yang berjumlah 67 orang. Adapun sampel yang digunakan berjumlah 67 orang dengan menggunakan sensus yaitu semua populasi dijadikan sampel. Teknik analisis data yang digunakan adalah analisis regresi berganda dengan alat bantu perangkat lunak SPSS 20. Hasil pengujian secara parsial menunjukkan bahwa: (1) Independensi berpengaruh negatif dan tidak signifikan terhadap kualitas audit pada Inspektorat Musi Banyuasin Sekayu, (2) Akuntabilitas berpengaruh positif dan tidak signifikan terhadap kualitas audit pada Inspektorat Musi Banyuasin Sekayu, (3) Time Pressure berpengaruh positif dan signifikan terhadap kualitas audit pada Inspektorat Musi Banyuasin Sekayu, (4) Due Professional Care berpengaruh positif dan tidak signifikan terhadap kualitas audit pada Inspektorat Musi Banyuasin Sekayu. Dan hasil pengujian secara simultan juga menunjukkan bahwa Independensi, Akuntabilitas, Time Pressure dan Due Professional care berpengaruh positif dan signifikan terhadap kualitas audit pada Inspektorat Musi Banyuasin Sekayu.
\end{abstract}

Kata kunci: Independensi, Akuntabilitas, Time Pressure Due Professional care, dan kualitas audit 


\section{Pendahuluan}

Auditor merupakan suatu profesi yang salah satu tugasnya adalah memeriksa laporan keuangan yang disajikan secara wajar sesuai dengan Standar Akuntansi Keuangan (SAK) atau Prinsip Akuntansi Berterima Umum (PABU). Disamping itu auditor harus bisa mempertahankan sikap objektif dan sikap independen.

Auditor merupakan profesi yang dipercayai oleh masyarakat. Masyarakat mengharapkan agar auditor tidak memihak terhadap informasi yang disajikan oleh pihak manajemen perusahaan dalam laporan keuangan. Kepercayaan yang besar dari pemakai laporan keuangan auditan dan jasa lainnya yang diberikan oleh akuntan publik inilah yang pada akhirnya mengharuskan akuntan publik memperlihatkan kualitas audit yang dihasilkannya (Hardiningsih, 2010). Hal ini dikarenakan banyaknya penyimpangan yang melibatkan akuntan publik, sehingga kualitas audit yang baik akan menjadi faktor utama kepercayaan masyarakat dalam menggunakan jasa audit. Saat ini para akuntan publik dalam menghasilkan kualitas audit tengah menjadi sorotan masyarakat banyak seperti beberapa kasus yang terjadi di Indonesia yaitu (1) Kasus kredit macet BRI Cabang Jambi pada tahun 2010, tentang tidak disajikannya laporan keuangan secara lengkap oleh akuntan publik, serta adanya penyalah gunaan kredit yang diajukan oleh tersangka. (2) Kasus Melinda Dee, tentang pemalsuan tanda tangan nasabah dalam formulir transfer dimana pemalsuan dilakukan sebanyak enam kali. (3) Kasus Mulyana W Kusuma (Anggota KPU 2004), tentang penyuapan anggota BPK (Badan Pemeriksa Keuangan) yang pada saat itu melaksanakan audit keuangan terhadap pengadaan logistik pemilu. Logistik pemilu tersebut berupa kotak suara, surat suara, tinta, serta teknologi informasi. Mulyana W Kusuma ditangkap karena tuduhan akan melakukan tindakan penyuapan kepada salah satu anggota tim auditor dari BPK yaitu Salman Khairiansyah (kompas.com). Disamping itu, AAA Financial Accounting Commite (2000) dalam jurnal Christiawan (2002) yang menyatakan kualitas audit ditentukan oleh dua hal diantaranya adalah kompetensi dan independensi. Kedua hal ini berpengaruh langsung terhadap kualitas audit.

Terungkapnya beberapa skandal seperti inilah yang menyebabkan merosotnya kepercayaan masyarakat, hal ini ditandai dengan turunnya harga saham secara drastis pada perusahaan yang terkena kasus tersebut. Oleh karena itu, untuk membentuk kepercayaan masyarakat, auditor harus berpedoman pada standar audit yang sudah ditetapkan oleh IAPI (Institut Akuntan Publik Indonesia) yaitu standar umum, standar pekerjaan lapangan dan standar pelaporan. Standar Umum yang merupakan suatu cerminan kualitas pribadi yang harus dimiliki oleh seorang auditor yang mengharuskan agar para auditor memiliki keahlian dan pelatihan teknis yang cukup dalam melaksanakan prosedur audit. Sementara itu, standar pekerjaan lapangan dan standar pelaporan digunakan untuk mengatur para auditor dalam hal mengumpulkan data dan melaksanakan kegiatan lainnya yang dilaksanakan selama audit berlangsung dan mewajibkan para auditor menyusun laporan atas laporan keuangan secara keseluruhan berdasarkan laporan yang diauditnya. Selain ketiga standar audit tersebut, ada hal-hal 
yang harus diperhatikan oleh akuntan publik dimana akuntan publik juga harus mematuhi kode etik profesi yang mengatur tentang tanggung jawab profesi (akuntabilitas), kompetensi dan kehati-hatian / kemahiran profesi yang cermat (due professional care) dalam melakukan audit, akuntan publik harus memiliki perilaku yang profesional, dan mampu bekerja dengan tepat waktu (time pressure).

\subsection{Kualitas Audit}

Menurut Arens, Elder, dan Beasley (2011) audit adalah pengumpulan data dan evaluasi bukti tentang informasi untuk menentukan dan melaporkan derajat kesesuaian antara informasi itu dan kriteria yang telah ditetapkan. Audit harus dilakukan oleh orang yang kompeten dan independen. Sedangkan definisi lain yang dikemukakan oleh Agoes (2004) mengemukakan bahwa auditing merupakan "suatu pemeriksaan yang dilakukan secara kritis dan sistematis oleh pihak yang independen, terhadap laporan keuangan yang telah disusun oleh manajemen beserta catatan-catatan pembukuan dan bukti-bukti pendukungnya, dengan tujuan untuk dapat memberikan pendapat mengenai kewajaran laporan keuangan tersebut. Audit bertujuan untuk menyatakan suatu pendapat atas kewajaran dalam semua hal material baik dari posisi keuangan, hasil usaha dan arus kas yang sesuai dengan prinsip-prinsip akuntansi yang berlaku umum.

Pada dasarnya, audit bukan hanya merupakan suatu proses review terhadap laporan keuangan tetapi juga mengenai pengkomunikasian yang tepat terhadap pihakpihak yang berkepentingan. Hal inilah yang digunakan sebagai dasar pengukuran kualitas audit. Menurut De Angelo (1981) dalam jurnalnya yang berjudul Auditor Independence, "Low Balling", and Disclosure Regulation. Mendefinisikan kualitas audit sebagai probabilitas yang mana seorang auditor menemukan dan melaporkan adanya penyimpangan dalam sistem akuntansi kliennya. De Angelo beragumentasi bahwa kualitas audit berhubungan dengan ukuran dari perusahaan audit, dengan proksi untuk ukuran perusahaan audit adalah jumlah klien. Perusahaan audit yang besar adalah dengan jumlah klien yang lebih banyak.

Ada empat hal yang dianggap memiliki hubungan dengan kualitas audit menurut Dies and Groux (1992) yaitu :

1. Lama waktu auditor melakukan pemeriksaan terhadap suatu perusahaan, semakin lama seorang auditor telah melakukan audit pada klien yang sama maka akan menghasilkan kualitas audit yang semakin rendah

2. Jumlah klien, semakin banyak jumlah klien maka kualitas audit semakin baik karena auditor akan berusaha menjaga reputasinya,

3. Kesehatan keuangan klien, semakin sehat kondisi keuangan klien maka ada kecenderungan klien tersebut menekan auditor agar tidak mengikuti standar

4. Review oleh pihak ketiga, kualitas audit akan meningkat jika auditor mengetahui bahwa hasil pekerjaannya akan diriview oleh pihak ketiga.

Untuk meningkatkan kepercayaan masyarakat terhadap auditor maka peran auditor untuk meningkatkan kualitas audit sangat diperlukan. Kualitas audit yang baik akan meningkatkan kepercayaan masyarakat untuk menggunakan jasa audit.

\subsection{Independensi}

Independensi yang berarti bahwa akuntan publik tidak mudah dipengaruhi (Hardiningsih, 2010). Manurut Badjuri (2011) yang mengatakan bahwa independensi 
dalam The CPA Handbook menurut E.B Wilcox merupakan standar auditing yang bertujuan untuk menambah kredibilitas laporan keuangan yang disajikan oleh manajemen. Sedangkan menurut Mulyadi (1998) menyatakan bahwa independensi juga berarti adanya kejujuran dalam diri auditor dalam mempertimbangkan fakta dan adanya pertimbangan yang objektif tidak memihak dalam diri auditor dalam merumuskan dan menyatakan pendapatnya.

Akuntan publik tidak dibenarkan memihak kepentingan siapapun. Akuntan publik berkewajiban untuk jujur tidak hanya kepada manajemen dan pemilik perusahaan, namun juga kepada kreditur dan pihak lain yang meletakkan kepercayaan atas pekerjaan akuntan publik (Christiawan, 2002). Sikap auditor dapat menghindarkan hubungan yang mungkin mengganggu objektivitas auditor. Independensi mencakup dua aspek menurut Badjuri (2011) yaitu:

1. Independensi dalam fakta (in fact), merupakan kemampuan auditor untuk bersikap bebas, jujur dan objektif dalam melakukan penugasan audit.

2. Independensi dalam penampilan (in appearance), merupakan independensi yang dipandang dari pihak-pihak yang berkepentingan terhadap perusahaan yang di audit yang mengetahui hubungan antara auditor dengan kliennya.

\subsection{Akuntabilitas}

Menurut Tetclock (1987) dalam Mardisar dan Sari (2007) akuntabilitas merupakan dorongan psikologi sosial yang dimiliki seseorang untuk mempertanggungjawabkan sesuatu yang telah mereka kerjakan kepada lingkungannya. Seseorang yang akuntabilitasnya tinggi yakin bahwa pekerjaan mereka akan dinilai oleh pihak lain yang kompeten dibanding yang akuntabilitasnya rendah (Tan dan Alison, 1999) dalam Badjuri (2011). Seorang auditor dituntut untuk menjunjung tinggi akuntabilitas, hal ini dikarenakan mereka bekerja sebagai perwakilan publik.

Dalam penelitian yang dilakukan oleh Cloyd (1997) dan penelitian Tan dan Alison (1999) dalam Mardisar dan Sari (2007) mengukur akuntabilitas dengan tiga indikator yaitu:

1. Motivasi

2. Keyakinan, dan daya pikir.

\subsection{Time Pressure}

Time pressure (tekanan waktu) adalah suatu kondisi dimana seorang auditor mendapatkan tekanan dari Kantor Akuntan Publik (KAP) tempat mereka bekerja untuk menyelesaikan audit pada waktu dan anggaran biaya yang telah ditetapkan sebelumnya. Time Pressure yang diberikan oleh Kantor Akuntan Publik (KAP) kepada auditornya bertujuan untuk mengurangi biaya audit. Adanya time pressure ini memaksa auditor agar dapat menyelesaikan tugas sesuai dengan anggaran waktu yang telah ditetapkan.

Menurut De Zoort dan Lord dalam Sitorus (2016) menyebutkan bahwa saat menghadapi tekanan anggaran waktu, auditor akan memberikan respon dengan dua cara yaitu, fungsional dan disfungsional. Tipe fungsional adalah perilaku auditor untuk bekerja lebih baik dan menggunakan waktu sebaik-baiknya sedangkan tipe disfungsional adalah sebaliknya.

\subsection{Due Professional Care}


Menurut Kurnia dan Suhayati (2010) menyatakan bahwa due professional care merupakan penggunaan kemahiran profesional dengan cermat dan seksama menekankan tanggung jawab setiap profesional yang bekerja dalam organisasi auditor independen untuk mengamati standar pekerjaan lapangan dan standar pelaporan. Kecermatan mengharuskan auditor untuk selalu waspada terhadap suatu resiko. Dengan adanya sikap cermat, maka auditor akan mampu mengungkap berbagai penyimpangan yang ada dalam laporan keuangan dengan lebih cepat dan mudah. Oleh karena itu, dalam mengevaluasi bukti audit, seorang auditor dituntut untuk memiliki keyakinan.

\subsection{Kerangka Penelitian}

Gambar 1 yang menyajikan Kerangka Pemikiran penelitian ini sebagai berikut:

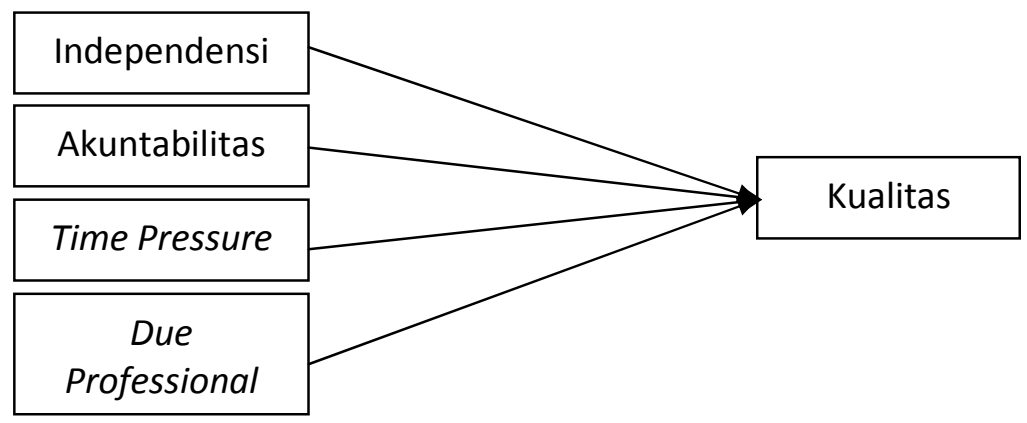

Gambar 1. Kerangka Pemikiran

Sumber : Data primer yang diolah (2019)

\subsection{Hipotesis Penelitian} berikut:

Hipotesis yang ingin diharapkan dalam penelitian ini dapat dijabarkan sebagai

1. Variabel Independensi berpengaruh terhadap Kualitas Audit pada Inspektorat Musi Banyuasin Sekayu

2. Variabel Akuntabilitas berpengaruh terhadap Kualitas Audit pada Inspektorat Musi Banyuasin Sekayu

3. Variabel Time Pressure berpengaruh terhadap Kualitas Audit pada Inspektorat Musi Banyuasin Sekayu

4. Variabel Due Professional Care berpengaruh terhadap Kualitas Audit pada Inspektorat Musi Banyuasin Sekayu

\section{Metode Penelitian}

Penelitian ini dilakukan di Inspektorat Musi Banyuasin Sekayu. Teknik pengumpulan data primer dilakukn dengan metode survey lapangan yaitu dengan menyebarkan kuesioner kepada auditor di Inspektorat Musi Banyuasin Sekayu.

Populasi penelitian ini adalah auditor Inspektorat Musi Banyuasin dan penyebaran kuesioner dilakukan sebanyak 67 responden. Jenis Sampel yang digunakan adalah sampel sensus, dimana seluruh populasi dijadikan sampel. Sampel penelitian ini berjumlah 67 sampel.

Instrumen penelitian yang digunakan dalam penelitian ini adalah kuesioner, yang berisi mengenai pertanyaan dan pernyataan yang akan dijawab responden. Dengan menggunakan skala ordinal. 
Teknik analisis data yang digunakan dalam penelitian ini adalah uji validitas dan reliabilitas. Kemudian dilakukan uji asumsi klasik yang terdiri dari uji normalitas, uji multikolinieritas dan uji heteroskedastisitas

Uji regresi digunakan untuk meramalkan suatu variabel (variabel dependent) bedasarkan satu variabel atau beberapa variabel lain (variabel independent) dalam suatu persamaan linear, yaitu: $Y=a+b_{1} X_{1}+b_{2} X_{2} \ldots+b_{n} X_{n}$ persamaan linear dengan beberapa variabel independent. (Trihendradi C, 2013:155). Teknik analisis datanya menggunakan model regresi linear berganda (multiple linear regression). Model yang digunakan adalah sebagai berikut:

Dimana :

$$
\mathrm{Y}=\mathrm{b}_{1} \mathrm{X}_{1}+\mathrm{b}_{2} \mathrm{X}_{2}+\mathrm{b}_{3} \mathrm{X}_{3}+\mathrm{b}_{4} \mathrm{X}_{4+e}
$$

$\mathrm{Y}=$ Kualitas Audit

$\mathrm{b}=$ Koefisien regresi variabel $\mathrm{X}$

$\mathrm{X}_{1}=$ Independensi

$\mathrm{X}_{2}=$ Akuntabilitas

$\mathrm{X}_{3}=$ Time Pressure

$\mathrm{X}_{4}=$ Due Professional Care

$\mathrm{e}=$ error $/$ variabel pengganggu

\section{Hasil dan Pembahasan}

\section{Distribusi Kuesioner Penelitian}

Pengumpulan data dilaksanakan pada penelitian ini melalui penyebaran kuesioner secara langsung kepada responden yang dalam hal ini adalah Auditor di Inspektorat Musi Banyuasin Sekayu. Penyebaran kuesioner sebanyak 67 responden. Distribusi hasil penelitian disajikan sebagai berikut:

Tabel 1

Deskripsi Kuesioner

\begin{tabular}{|c|c|c|c|c|c|}
\hline Responden & $\begin{array}{c}\text { Kuesioner } \\
\text { disebarkan }\end{array}$ & $\begin{array}{c}\text { Kuesioner } \\
\text { kembali }\end{array}$ & $\begin{array}{c}\text { Kuesioner } \\
\text { tidak } \\
\text { kembali }\end{array}$ & $\begin{array}{c}\text { Kuesioner } \\
\text { yang tidak } \\
\text { dapat diolah }\end{array}$ & $\begin{array}{c}\text { Kuesioner } \\
\text { yang dapat } \\
\text { diolah }\end{array}$ \\
\hline Auditor & 67 & 36 & 31 & 3 & 33 \\
\hline
\end{tabular}

Sumber: Data diolah oleh peneliti (2019)

Dari tabel 1 diatas dapat diketahui bahwa jumlah kuesioner yang disebarkan sebanyak 67, dan yang dikembalikan sebanyak 36 kuesiner, kemudian 31 kuesioner yang tidak kembali. Dari 36 kuesioner yang kembali, terdapat 3 kuesioner yang tidak dapat diolah dikarenakan pengisian data tidak lengkap. Sehigga kuesioner yang dapat dijadikan diolah sebanyak 33 responden.

Berikut ini adalah profil responden yang penulis dapatkan berdasarkan informasi dalam kuesioner yang diisi oleh responden tersebut.

Tabel 2

Profil Umum Responden

\begin{tabular}{|l|c|c|}
\hline \multicolumn{1}{|c|}{ Keterangan } & Jumlah & Persentase \\
\hline Usia : & & \\
a. $<30$ tahun & 6 & $18,18 \%$ \\
b. 30-45 tahun & 22 & $66,67 \%$ \\
c. $>45$ tahun & 5 & $15,15 \%$ \\
\hline
\end{tabular}




\begin{tabular}{|c|c|c|}
\hline Total & 33 & $100 \%$ \\
\hline $\begin{array}{l}\text { Jenis Kelamin : } \\
\text { a. Laki-laki } \\
\text { b. Perempuan }\end{array}$ & $\begin{array}{l}18 \\
15 \\
\end{array}$ & $\begin{array}{l}54,54 \% \\
45,46 \%\end{array}$ \\
\hline Total & 33 & $100 \%$ \\
\hline $\begin{array}{l}\text { Jabatan : } \\
\text { a. Auditor pertama } \\
\text { b. Auditor Muda } \\
\text { c. Auditor Madya } \\
\text { d. Auditor Penyelia }\end{array}$ & $\begin{array}{c}17 \\
11 \\
3 \\
2 \\
\end{array}$ & $\begin{array}{c}51,51 \% \\
33,33 \% \\
9,09 \% \\
6,07 \% \\
\end{array}$ \\
\hline Total & 33 & $100 \%$ \\
\hline $\begin{array}{l}\text { Lama Jabatan : } \\
\begin{array}{l}\text { a. }<10 \text { tahun } \\
\text { b. } 11-30 \text { tahun } \\
\text { c. }>30 \text { tahun }\end{array}\end{array}$ & $\begin{array}{c}16 \\
17 \\
0\end{array}$ & $\begin{array}{c}48,49 \% \\
51,51 \% \\
0\end{array}$ \\
\hline Total & 33 & $100 \%$ \\
\hline
\end{tabular}

Sumber : Data diolah dari data primer (2019)

Berdasarkan tabel 2 diatas terlihat bahwa terlihat bahwa sebagian besar usia auditor yang berpartisipasi sebagai responden dalam penelitian ini adalah antara $<30$ tahun sebanyak 6 orang $(18,18 \%), 31-45$ tahun sebanyak 22 orang $(66,67 \%)$ dan $>45$ tahun sebanyak 5 orang $(15,15 \%)$. Jenis kelamin laki-laki sebanyak $18(54,54 \%)$ dan perempuan sebanyak 15 $(45,46 \%)$. Kemudian jabatan auditor sebagai auditor pertama sebanyak 17 (51,51\%), auditor muda sebanyak $11(33,33 \%)$, auditor madya sebanyak $3(9,09 \%)$ dan auditor penyelia sebanyak $2(6,07 \%)$. Sedangkan lama jabatan sebagai auditor $<10$ tahun sebanyak 16 (48,49\%), 11-30 tahun sebanyak 17 (51,51\%), dan tidak ada auditor yang mengisi responden dengan lama jabatan $>30$ tahun sebanyak $0(0 \%)$.

\section{Deskripsi Statistik Kuantitatif}

\section{Hasil Validasi}

Uji validitas digunakan untuk mengetahui apakah suatu instrumen alat ukur telah menjalankan fungsi ukurnya. Uji validitas dinyatakan dalam indeks diskriminasi item minimal 0 , sedangkan koefisien yang $<0.25$ dinyatakan gugur, $\geq 0.25$ dinyatakan valid. (Sugiyono, 2010). Dalam pengujian ini, pengujian validitas variabel Independensi (X1), Akuntabilitas (X2), Time Pressure (X3), Due Professional Care (X4) dan Kualitas Audit (Y) dapat dilihat pada tabel berikut:

Tabel 3

Hasil Uji Validitas Instrumen Penelitian

\begin{tabular}{|l|c|c|c|c|}
\hline \multicolumn{1}{|c|}{ Variabel } & Indikator & $\mathrm{r}_{\text {hitung }}$ & $\mathrm{r}_{\text {table }}$ & Keterangan \\
\hline Independensi & Independensi 1 & 0,751 & 0,2913 & Valid \\
(X1) & Independensi 2 & 0,678 & 0,2913 & Valid \\
& Independensi 3 & 0,838 & 0,2913 & Valid \\
& Independensi 4 & 0,640 & 0,2913 & Valid \\
& Independensi 5 & 0,625 & 0,2913 & Valid \\
& Independensi 6 & 0,708 & 0,2913 & Valid \\
& Independensi 7 & 0,538 & 0,2913 & Valid \\
& Independensi 8 & 0,535 & 0,2913 & Valid \\
\hline
\end{tabular}




\begin{tabular}{|c|c|c|c|c|}
\hline & $\begin{array}{l}\text { Independensi } 9 \\
\text { Independensi } 10 \\
\text { Independensi } 11 \\
\text { Independensi } 12 \\
\text { Independensi } 13 \\
\text { Independensi } 14\end{array}$ & $\begin{array}{l}0,654 \\
0,491 \\
0,689 \\
0,440 \\
0,838 \\
0,833 \\
\end{array}$ & $\begin{array}{l}0,2913 \\
0,2913 \\
0,2913 \\
0,2913 \\
0,2913 \\
0,2913 \\
\end{array}$ & $\begin{array}{l}\text { Valid } \\
\text { Valid } \\
\text { Valid } \\
\text { Valid } \\
\text { Valid } \\
\text { Valid }\end{array}$ \\
\hline $\begin{array}{l}\text { Akuntabilitas } \\
\text { (X2) }\end{array}$ & $\begin{array}{l}\text { Akuntabilitas } 1 \\
\text { Akuntabilitas } 2 \\
\text { Akuntabilitas } 3 \\
\text { Akuntabilitas } 4 \\
\text { Akuntabilitas } 5 \\
\text { Akuntabilitas } 6 \\
\text { Akuntabilitas } 7 \\
\text { Akuntabilitas } 8 \\
\end{array}$ & $\begin{array}{l}0,766 \\
0,563 \\
0,794 \\
0,641 \\
0,725 \\
0,854 \\
0,623 \\
0,532 \\
\end{array}$ & $\begin{array}{l}0,2913 \\
0,2913 \\
0,2913 \\
0,2913 \\
0,2913 \\
0,2913 \\
0,2913 \\
0,2913 \\
\end{array}$ & $\begin{array}{l}\text { Valid } \\
\text { Valid } \\
\text { Valid } \\
\text { Valid } \\
\text { Valid } \\
\text { Valid } \\
\text { Valid } \\
\text { Valid }\end{array}$ \\
\hline $\begin{array}{l}\text { Time Pressure } \\
\text { (X3) }\end{array}$ & $\begin{array}{l}\text { Time Pressure } 1 \\
\text { Time Pressure } 2 \\
\text { Time Pressure } 3 \\
\text { Time Pressure } 4 \\
\text { Time Pressure } 5 \\
\text { Time Pressure } 6 \\
\text { Time Pressure } 7\end{array}$ & $\begin{array}{l}0,495 \\
0,537 \\
0,621 \\
0,593 \\
0,620 \\
0,702 \\
0,828\end{array}$ & $\begin{array}{l}0,2913 \\
0,2913 \\
0,2913 \\
0,2913 \\
0,2913 \\
0,2913 \\
0,2913\end{array}$ & $\begin{array}{l}\text { Valid } \\
\text { Valid } \\
\text { Valid } \\
\text { Valid } \\
\text { Valid } \\
\text { Valid } \\
\text { Valid }\end{array}$ \\
\hline $\begin{array}{l}\text { Due } \\
\text { Professional } \\
\text { Care (X4) }\end{array}$ & $\begin{array}{c}\text { Due Professional Care } 1 \\
\text { Due Professional Care } 2 \\
\text { Due Professional Care } 3 \\
\text { Due Professional Care } 4 \\
\text { Due Professional Care } 5 \\
\text { Due Professional Care } 6 \\
\text { Due Professional Care } 7 \\
\text { Due Professional Care } 8\end{array}$ & $\begin{array}{l}0,747 \\
0,628 \\
0,594 \\
0,367 \\
0,819 \\
0,611 \\
0,747 \\
0,515\end{array}$ & $\begin{array}{l}0,2913 \\
0,2913 \\
0,2913 \\
0,2913 \\
0,2913 \\
0,2913 \\
0,2913 \\
0,2913\end{array}$ & $\begin{array}{l}\text { Valid } \\
\text { Valid } \\
\text { Valid } \\
\text { Valid } \\
\text { Valid } \\
\text { Valid } \\
\text { Valid } \\
\text { Valid }\end{array}$ \\
\hline $\begin{array}{l}\text { Kualitas Audit } \\
\text { (Y) }\end{array}$ & $\begin{array}{l}\text { Kualitas Audit } 1 \\
\text { Kualitas Audit } 2 \\
\text { Kualitas Audit } 3 \\
\text { Kualitas Audit } 4 \\
\text { Kualitas Audit } 5 \\
\text { Kualitas Audit } 6 \\
\text { Kualitas Audit } 7 \\
\text { Kualitas Audit } 8 \\
\text { Kualitas Audit } 9\end{array}$ & $\begin{array}{l}0,594 \\
0,566 \\
0,731 \\
0,557 \\
0,654 \\
0,585 \\
0,724 \\
0,461 \\
0,706\end{array}$ & $\begin{array}{l}0,2913 \\
0,2913 \\
0,2913 \\
0,2913 \\
0,2913 \\
0,2913 \\
0,2913 \\
0,2913 \\
0,2913\end{array}$ & $\begin{array}{l}\text { Valid } \\
\text { Valid } \\
\text { Valid } \\
\text { Valid } \\
\text { Valid } \\
\text { Valid } \\
\text { Valid } \\
\text { Valid } \\
\text { Valid }\end{array}$ \\
\hline
\end{tabular}

Sumber: Data olahan SPSS, 2019

Berdasarkan tabel 3 perhitunhan diatas, nilai $\mathrm{r}$ tabel untuk $\mathrm{N}=33$ dengan tingkat signifikansi 0,05 adalah 0,2913. Pada tabel uji validitas di atas dapat dilihat nilai Corrected item-Total Correlation untuk butir-butir pernyataan tentang Kualitas Audit di Inspektorat Musi Banyuasin Sekayu berkisar antara 0.367 sampai dengan 0.854 , seluruh hasil uji $\mathrm{r}_{\text {hitung }}$ $>0,2913$. Dari hasil uji validitas secara umum semua pertanyaan mengenai Kualitas Audit di Inspektorat Musi Banyuasin Sekayu adalah valid.

\section{Uji Reliabilitas}


Uji reliabilitas digunakan untuk mengetahui konsistensi alat ukur, apakah alat pengukuran yang digunakan dapat diandalkan dan tetap konsisten jika pengukurannya tersebut diulang. Untuk mengetahui nilai reliability dapat dikatakan reliabel jika pada tabel cronbach's alpha nilainya $>0,6$ maka pengujian tersebut dapat dikatakan reliabel. Reliabilitas dapat diukur dengan uji statistik cronbach alpha, yang dapat dilihat pada tabel berikut:

Tabel 4

Hasil Uji Reliabilitas Statistik

\begin{tabular}{|l|c|c|c|}
\hline \multicolumn{1}{|c|}{ Keterangan } & $\begin{array}{c}\text { Cronbach's } \\
\text { Alpha }\end{array}$ & N of Item & Kriteria \\
\hline Independensi (X1) & .902 & 14 & Reliabel \\
\hline Akuntabilitas (X2) & .833 & 8 & Reliabel \\
\hline Time Pressure (X3) & .741 & 7 & Reliabel \\
\hline Due Professional Care (X4) & .788 & 8 & \\
\hline Kualitas Audit (Y) & .799 & 9 & Reliabel \\
\hline
\end{tabular}

Sumber: Data diolah 2019

Berdasarkan tabel 5.4 diatas, dapat dilihat bahwa nilai cronbach alpha untuk variabel Independensi (X1) sebesar 0,902, Akuntabilitas (X2) sebesar 0,833, Time Pressure (X3) sebesar 0,741, Due Professional Care (X4) sebesar 0,788 dan kualitas audit (Y) sebesar 0,799, masing-masing variabel tersebut memiliki nilai $>0,6$, hal ini berarti bahwa hasil pengujian dinyatakan reliabel.

\section{Uji Asumsi Klasik}

Uji Normalitas

Uji normalitas dilakukan untuk mengetahui apakah variabel terikat dengan variabel bebas terdistribusi secara normal. Model regresi yang baik adalah model regresi yang berdistribusi normal. Untuk menguji normalitas data dalam penelitian ini dilihat dari tabel one-sample Kolmogorov-Smirnov Test, pada kolom Unstandardized Residual berikut:

Tabel 5 Hasil Uji Normalitas

One-Sample Kolmogorov-Smirnov Test

\begin{tabular}{|c|c|c|}
\hline & & $\begin{array}{l}\text { Unstandardized } \\
\text { Residual }\end{array}$ \\
\hline $\mathrm{N}$ & & 33 \\
\hline Normal Parameters ${ }^{a, b}$ & Mean & $0 \mathrm{E}-7$ \\
\hline & Std. Deviation & 1,25403533 \\
\hline & Absolute & ,110 \\
\hline Most Extreme Differences & $\begin{array}{l}\text { Positive } \\
\text { Negative }\end{array}$ & $\begin{array}{r}, 110 \\
-, 069\end{array}$ \\
\hline Kolmogorov-Smirnov Z & & ,629 \\
\hline Asymp. Sig. (2-tailed) & & ,823 \\
\hline
\end{tabular}

Berdasarkan tabel 5.5 diatas dapat disimpulkan bahwa data penelitian berdistribusi normal dengan nilai sig. 0,823 atau $>0,5$. 


\section{Uji Multikolinieritas}

Uji multikolinieritas merupakan uji yang ditunjuk untuk menguji apakah model regresi ditemukan adanya korelasi antara variabel bebas. Untuk dapat mendeteksi ada atau tidaknya multikolinieritas di dalam model regresi adalah melihat nilai Tolerance dan VIF ( Variance Inflation Factor) melalui program SPSS. Tolerance mengukur variabilitas variabel terpilih yang tidak dijelaskan oleh variabel independen lainnya, Niali yang umum dipakai untuk menunjukkan adannya multikonilieritas adalah tolerance $<0,1$ atau sama dengan nilai VIF $>10$. Dan sebaliknya apabila nilai tolerance $>0,1$ dan VIF $<10$ maka tidak terjadi multikolinieritas (Drapper dan Smith, 1998). Berdasarkan hasil pengujian dalam penelitian ini dapat dilihat pada tabel berikut:

Tabel 6

\section{Hasil Uji Multikolinearitas}

\begin{tabular}{|l|r|r|}
\hline \multicolumn{2}{|c|}{ Model } & \multicolumn{2}{|c|}{ Coefficients $^{\text {a }}$} \\
\cline { 2 - 3 } & Collinearity Statistics \\
\cline { 2 - 3 } & Tolerance & \multicolumn{1}{|c|}{ VIF } \\
(Constant) & & \\
Independensi &, 093 & 10,808 \\
Akuntabilitas &, 112 & 8,906 \\
Time Pressure &, 116 & 8,623 \\
Due Professional Care &, 107 & 9,374 \\
\hline
\end{tabular}

a. Dependent Variable: Kualitas Audit

Berdasarkan tabel 5.6 diatas, dapat dilihat bahwa nilai VIF pada variabel independensi (X1) adalah 10,808, variabel akuntabilitas (X2) adalah 8,906, time pressure (X3) adalah 8,623 dan variabel Due Professional Care (X4) adalah 9,374, semua variabel tersebut $<10$, maka hasil pengujian tersebut dinyatakan tidak terjadi multikolinieritas, hal ini berarti bahwa nilai regresinya sudah baik. Sedangkan nilai tolerance variabel $\mathrm{X}_{1}, \mathrm{X}_{2}, \mathrm{X}_{3}$, dan $\mathrm{X}_{4}$ adalah $0.093,0.112,0.116$, dan 0.107 yang berarti memiliki nilai $>0.05$ sehingga dapat disimpulkan bahwa tidak terjadi multikolinieritas.

\section{Uji Heteroskedastisitas}

Uji heteroskedastisitas adalah suatu keadaan dimana varians dan kesalahan pengganggu tidak konstan untuk semua variabel bebas. Model regresi yang baik adalah yang tidak terjadi heteroskedastisitas. Apabila probabilitas hasil korelasi lebih besar dari 0,05 $(5 \%)$, maka persamaan regresi tersebut tidak mengandung heterokedastisitas. Hasil pengujian dalam penelitian ini dilihat pada tabel berikut:

Tabel 7

Coefficients $^{a}$

\begin{tabular}{|l|r|r|r|r|r|}
\hline Model & \multicolumn{2}{|c|}{$\begin{array}{c}\text { Unstandardized } \\
\text { Coefficients }\end{array}$} & $\begin{array}{l}\text { Standardized } \\
\text { Coefficients }\end{array}$ & T & \multirow{2}{*}{ Sig. } \\
\cline { 2 - 4 } & \multicolumn{1}{|c|}{ B } & Std. Error & Beta & & \\
\hline (Constant) & $-2,220$ & 1,452 & & $-1,529$ &, 137 \\
Independensi &,- 004 &, 071 &,- 033 &,- 061 &, 952
\end{tabular}




\begin{tabular}{l|r|r|r|r|r|} 
Akuntabilitas &,- 056 &, 111 &,- 253 &,- 507 &, 616 \\
Time Pressure &,- 008 &, 147 &,- 027 &,- 056 &, 956 \\
Due Professional Care &, 176 &, 120 &, 746 & 1,459 &, 156 \\
\hline
\end{tabular}

a. Dependent Variable: RES2

Berdasarkan tabel 7 dapat diketahui bahwa nilai signifikansi keempat variabel independen $>0,05$. Sehingga dapat disimpulkan bahwa hasil uji penelitian ini tidak terjadi heteroskedastisitas.

\section{Hasil Uji Regresi Linier Berganda}

Analisis regresi linier berganda merupakan metode statistik atau analisis yang digunakan untuk menjelaskan ataupun memprediksi variabel dependen berdasarkan variabel independen.

Tabel 8

Nilai a dan b Untuk Persamaan Regresi Y

Coefficients $^{\mathrm{a}}$

\begin{tabular}{|l|r|r|r|r|r|}
\hline \multirow{2}{*}{ Model } & \multicolumn{2}{|c|}{$\begin{array}{c}\text { Unstandardized } \\
\text { Coefficients }\end{array}$} & $\begin{array}{c}\text { Standardized } \\
\text { Coefficients }\end{array}$ & \multicolumn{1}{c|}{ Sig. } & \\
\cline { 2 - 5 } & \multicolumn{1}{|c|}{ B } & Std. Error & \multicolumn{1}{c|}{ Beta } & \\
\hline (Constant) & $-5,359$ & 2,644 & & $-2,026$ &, 052 \\
Independensi &,- 095 &, 129 &,- 157 &,- 740 &, 466 \\
Akuntabilitas &, 151 &, 202 &, 144 &, 747 &, 461 \\
Time Pressure &, 944 &, 268 &, 667 & 3,527 &, 001 \\
Due Professional Care &, 349 &, 219 &, 313 & 1,589 &, 123 \\
\hline
\end{tabular}

a. Dependent Variable: Kualitas Audit

Sumber: Data diolah menggunakan SPSS 20 berikut:

Dari tabel 8 diatas, maka persamaan regresi dalam penelitian ini adalah sebagai

$$
Y=(-5,359)+(-0,95)\left(X_{1}\right)+0.151\left(X_{2}\right)+0.944\left(X_{3}\right)+0,349\left(X_{4}\right)+\varepsilon
$$

Dari persamaan diatas dapat disimpulkan sebagai berikut:

a. Nilai Konstanta

Nilai konstanta sebesar $-5,359$ hal ini menunjukkan bahwa variabel bebas (X1, X2, $\mathrm{X} 3$, dan $\mathrm{X} 4$ ) yang terdiri dari Independensi, akuntabilitas, time pressure, dan due professional care mampu memberikan kontribusi yang besar dalam mempengaruhi kualitas audit (variabel terikat) .

b. Nilai Variabel X1 (Independensi)

Nilai variabel X1 (Independensi) sebesar -0,95 artinya independensi memberikan kontribusi negatif dalam memengaruhi kualitas audit sebesar $-0,95$.

c. Nilai Variabel X2 (Akuntabilitas)

Nilai Variabel X2 (Akuntabilitas) sebesar 0.151 artinya komitmen organisasi memberikan kontribusi positif dalam memengaruhi kualitas audit sebesar 0.415.

d. Nilai Variabel X3 (Time Pressure)

Nilai Variabel X3 (Time Pressure) sebesar 0.944 artinya profesionalisme memberikan kontribusi positif dalam memengaruhi kualitas audit sebesar 0.944 .

e. Nilai Variabel X4 (Due Professional Care) 
Nilai Variabel X4 (Due Professional Care) sebesar 0.349 artinya profesionalisme memberikan kontribusi positif dalam memengaruhi kualitas audit sebesar 0.349.

\section{Hasil Uji Statistik F}

Uji $\mathrm{F}$ digunakan untuk mengetahui ada atau tidaknya pengaruh simultan (secara bersama-sama) variabel-variabel independen (Independensi, Akuntabilitas, Time Pressure, dan Due Professional Care) terhadap variabel dependen (kualitas audit). Hasil penelitian mengenai uji $\mathrm{F}$ variabel dependen terhadap variabel independen dalam penelitian ini dilihan pada tabel berikut:

Tabel 9

Hasil Uji F Variabel Independen terhadap Variabel Dependen ANOVA $^{\mathrm{a}}$

\begin{tabular}{|c|r|r|r|r|r|}
\hline Model & Sum of Squares & Df & Mean Square & F & Sig. \\
\hline \multirow{2}{*}{1 Regression } & 383,313 & 4 & 95,828 & 53,319 &, $000^{\mathrm{D}}$ \\
Residual & 50,323 & 28 & 1,797 & & \\
Total & 433,636 & 32 & & & \\
\hline
\end{tabular}

a. Dependent Variable: Kualitas Audit

b. Predictors: (Constant), Due Professional Care, Time Pressure , Akuntabilitas, Independensi

Sumber: Data Olahan SPSS, 2019.

Dari tabel 9 diatas, nilai signifikan lebih kecil dari $0.05(0.000<0.05)$, karena $\mathrm{F}_{\text {hitung }}>$ $\mathrm{F}_{\text {tabel }}(53,319>2,71)$, maka model regresi dapat digunakan untuk memprediksi Kualitas Audit Inspektorat Musi Banyuasin atau dapat dikatakan bahwa variabel X1 (Independensi), X2 (Akuntabilitas), X3 (Time Pressure), dan X4 (Due Professional Care) secara bersamasama berpengaruh signifikan terhadap variabel Y (Kualitas Audit Inspektorat Musi Banyuasin).

\section{Hasil Uji Statistik t}

Uji t digunakan untuk mengetahui pengaruh masing-masing variabel independen yaitu Independensi, Akuntabilitas, Time Pressure, dan Due Professional Care terhadap variabel dependen yaitu kualitas audit. Uji t dilakukan dengan membandingkan antara $t_{\text {hitung }}$ dengan $t$ tabel, dimana nilai $t$ tabel dalam penelitian ini 2.028 dengan tingkat signifikan $5 \%$ kriteria pengujian yang dilakukan adalah sebagai berikut:

a. Jika $\mathrm{t}_{\text {hitung }}>\mathrm{t}_{\text {tabel }}(\mathrm{n}-\mathrm{k}-\mathrm{l})$, jika $p$ value $<0,05$ maka Ho ditolak

b. Jika $\mathrm{t}_{\text {hitung }}<\mathrm{t}_{\text {tabel }}(\mathrm{n}-\mathrm{k}-\mathrm{l})$, jika $P$ value $>0.05$ maka Ho diterima

Dari hasil penelitian didapatkan bahwa koefisien regresi, nilai t dan signifikansi secara parsial adalah sebagai berikut:

\section{Tabel 10}

\section{Hasil Uji Parsial (Uji t)}

Coefficients $^{\mathrm{a}}$

\begin{tabular}{|l|r|r|r|r|r|}
\hline Model & \multicolumn{2}{|c|}{$\begin{array}{c}\text { Unstandardized } \\
\text { Coefficients }\end{array}$} & $\begin{array}{c}\text { Standardized } \\
\text { Coefficients }\end{array}$ & \multicolumn{1}{c|}{ Sig. } & \\
\cline { 2 - 4 } & \multicolumn{1}{|c|}{ B } & Std. Error & \multicolumn{1}{c|}{ Beta } & & \\
\hline 1 (Constant) & $-5,359$ & 2,644 & & $-2,026$ &, 052 \\
Independensi &,- 095 &, 129 &,- 157 &,- 740 &, 466 \\
\hline
\end{tabular}




\begin{tabular}{|l|r|r|r|r|r|} 
Akuntabilitas &, 151 &, 202 &, 144 &, 747 &, 461 \\
Time Pressure &, 944 &, 268 &, 667 & 3,527 &, 001 \\
Due Professional Care &, 349 &, 219 &, 313 & 1,589 &, 123 \\
\hline
\end{tabular}

a. Dependent Variable: Kualitas Audit

Sumber: Data diolah menggunakan SPSS 20.

Berdasarkan hasil pengujian parsial (uji t) dari tabel 10 diatas, dapat disimpulkan bahwa:

1. Variabel independensi memiliki nilai $\mathrm{t}_{\text {hitung }}<\mathrm{t}$ tabel dimana $-0,740<2.048$ dengan tingkat signifikani $0.466<0.05$. Hal ini berarti variabel $\mathrm{X}_{1}$ yaitu independensi tidak berpengaruh signifikan terhadap kualitas audit.

2. Variabel akuntabilitas memiliki nilai $\mathrm{t}$ hitung $<\mathrm{t}$ tabel dimana $0,747<2.048$ dengan tingkat signifikansi $0.461<0.05$. Hal ini berarti variabel $\mathrm{X}_{2}$ yaitu akuntabilitas tidak berpengaruh signifikan terhadap kualitas audit.

3. Variabel time pressure memiliki nilai $\mathrm{t}_{\text {hitung }}>\mathrm{t}$ tabel dimana 3,527 $>2.048$ dengan tingkat signifikansi $0.001>0.05$. Hal ini berarti variabel $\mathrm{X}_{3}$ yaitu time pressure berpengaruh signifikan terhadap kualitas audit.

4. Variabel due professional care memiliki nilai $\mathrm{t}_{\text {hitung }}<\mathrm{t}$ tabel dimana $1,589<2.048$ dengan tingkat signifikansi $0.123<0.05$. Hal ini berarti variabel $\mathrm{X}_{3}$ yaitu due professional care tidak berpengaruh signifikan terhadap kualitas audit.

\section{Pembahasan:}

1. Independen tidak memiliki pengaruh signifikan terhadap kualitas audit.

2. Akuntabilitas tidak memiliki pengaruh signifikan terhadap kualitas audit.

3. Time Pressure memiliki pengaruh signifikan terhadap kualitas audit.

4. Due Professional Care tidak memiliki pengaruh signifikan terhadap kualitas audit

5. Independensi, Akuntabilitas, Time Pressure dan Due Professional Care memiliki pengaruh positif dan signifikan terhadap kualitas audit.

\section{Kesimpulan}

Berdasarkan hasil analisis dan pembahasan maka dapat disimpulkan bahwa:

1. Secara simultan variabel independensi, akuntabilitas, time pressure dan due professional care memiliki pengaruh positif dan signifikan terhadap kualitas audit, hal ini dapat dilihat dari nilai $\mathrm{F}_{\text {hitung }}>\mathrm{F}_{\text {tabel }}$ yakni 53,319 $>2,71$ dengan tingkat signifikansi $0.000<0.05$.

2. Secara parsial variabel independen tidak memiliki pengaruh signifikan terhadap kualitas audit.

3. Secara parsial variabel akuntabilitas tidak memiliki pengaruh signifikan terhadap kualitas audit.

4. Secara parsial variabel time pressure memiliki pengaruh signifikan terhadap kualitas audit.

5. Secara parsial variabel due professional care tidak memiliki pengaruh signifikan terhadap kualitas audit.

\section{Saran} adalah:

Adapun saran yang dapat diberikan berdasarkan hasil penelitian yang telah dilakukan

1. Pada penelitian selanjutnya diharapkan agar melakukan penelitian dengan objek yg lebih luas dan responden yang lebih banyak. 
2. Hasil penelitian ini dapat menjadi masukan bagi para auditor agar meningkatkan kualitas audit.

\section{Ucapan Terima Kasih}

Terima Kasih tim peneliti ucapkan kepada Kementrian Ristekdikti yang telah memberikan dukungan moril dan bantuan Dana Penelitian untuk Penelitian Dosen Pemula (PDP) No. 108/SP2H/LT/DRPM/2019, tanggal 11 Maret 2019

\section{Referensi}

Agoes, Sukrisno. (2012). Auditing (Pemeriksaan Akuntan) oleh Kantor Akuntan Publik. Edisi ke 4. Lembaga Penerbit Fakultas Ekonomi Universitas Indonesia: Jakarta.

Alim, Nizarul., Hapsari, M.Trisnin., dan Purwanti, L.2007. Pengaruh Kompetensi Terhadap Kualitas Auditor dengan Etika Auditor sebagai Variabel Moderasi. SNA X Makasar. AUEP-08

Arens, A.A., Elder, R.J., Beasley, M.S. 2011. Auditing dan Pelayanan Verifikasi: Pendekatan Terpadu, alih bahasa oleh Tim Dejakarta, edisi kesembilan, Jakarta: Indeks.

Arisinta, Octaviana. 2013. Pengaruh Kompetensi, Independensi, Time Budget Pressure, dan Audit Fee Terhadap Kualitas Audit Pada Kantor Akuntan Publik di Surabaya. Jurnal Ekonomi dan Bisnis. Tahun XXIII, No. 3 Desember 2013.

Badjuri, Achmat. 2011. Faktor-faktor Yang Berpengaruh Terhadap Kualitas Audit Auditor Independen Pada Kantor Akuntan Publik (KAP) Di Jawa Tengah. Jurnal Dinamika Keuangan dan Perbankan, Nopember 2011, Hal: 183-197. Vol. 3 No 2, ISSN: 19794878 .

Christiawan, Y.J. 2002. Kompetensi dan Independensi Akuntan Publik: Refleksi Hasil Penelitian Empiris. Journal Directory : Kumpulan Jurnal Akuntansi dan Keuangan Unika Petra. Vol. 4 / No. 2.

Cloyd, Bryan C. 1997. Performance in Tax Research Tasks : The Joint Effect of Knowledge and Accountability. The Accounting Review. Vol.72 No.1. pp 111-131.

De Angelo, L.E. 1981. Auditor Independence, "Low Balling", And Disclosure Regulation. Journal Of Accounting And Economics. Vol 3, Issue 2, August 1981, Paces 113-127.

Dies, Donald L., Giroux, Gari A. 1992. Determinants of Audit Quality in The Puclic Sector. The Accounting Review. Vol 67 No. 3 (Juli). pp: 462-479.

Ghozali, Imam. 2005. Aplikasi Analisis Mutivariate dengan Program SPSS. Badan Penerbit Universitas Diponegoro : Semarang.

Halim, Abdul. 2008. Auditing (dasar-dasar Audit Laporan Keuangan). Yogyakarta: Unit Penerbit dan percetakan STIM YKPN. 
Hardiningsih, Pancawati. 2010. Pengaruh Independensi, Corporate Governance, dan Kualitas Audit Terhadap Integritas laporan Keuangan. Kajian Akuntansi, Pebruari 2010, Hal.61-76. Vol 2 No 1, ISSN: 1979-4886.

Jensen \& Meckling. 1976. The Theory of The Firm: Manajerial Behaviour, Agency Cost, and Ownership Structure. Journal of Financial and Economics. 3: 305-360.

Mardisar, Diani dan Sari, Nelly. 2007. Pengaruh Akuntabilitas dan Pengetahuan Terhadap Kualitas Hasil Kerja Auditor. SNA X Makasar. AUEP-11. 1-25.

Mulyadi dan Kanaka, Puradirejo. 1998. Auditing. Buku Satu Edisi Kelima. Salemba: Jakarta.

Rahayu, Siti Kurnia., dan Suhayati, Ely. 2010. Auditing: Konsep dasar dan pedoman pemeriksaan akuntan publik. Yogyakarta: Graha Ilmu.

Simamora, Jenry. 2002. Auditing. Jilid 1. UPP AMP YKPN.

Sitorus, Santa Ulina. 2016. Pengaruh Time Pressure, Audit Risk, Professional Commitment, Review Procedure and Quality Control dan Self Esteem in Relation To Ambition Terhadap Penghentian Prematur Atas Prosedur Audit (Premature Sign Off). JOM Fekon, Vol 3 No 1, Februari 2016.

Solomon, I., and Brown, C. Auditors Judgement and Decision Under Time Pressure: An Illustration and Agenda for Reaserch. Proceedings of The 1992 Deloitte \& Touche/University of Kansas Symposium on Auditing Problems. pp: 73-98,1992.

Sugiyono. 2007. Metode Penelitian Kuantitatif Kualitatif dan R\&D. Bandung: Alfabeta

Sugiyono. 2010. Metode Penelitian Kuantitatif Kualitatif dan R\&D. Bandung: CV Alfabeta

Tan, Tong Han dan Allison Kao. 1999. Accountability Effect on Auditor's Performance The Influence of Knowledge, Problem Solving Ability and Task Complexity. Journal of Accounting Research.

Tjun, Lauw Tjun., Marpaung, Elyzabet Indrawati., dan Setiawan, Santy. 2012. Pengaruh Kompetensi dan Independensi Auditor Terhadap Kualitas Audit. Jurnal Akuntansi, Vol 4 No 1 Mei 2002:33-56.

Tetclock, P.E dan J.L. Kim. 1987. Accountability and Judgment Processes In A Personality Prediction Task. Journal of Personality and Social psychology (April): 700-709.

Trisnaningsih, Sri. 2007. Independensi Auditor dan Komitmen Organisasi sebagai Mediasi Pengaruh Pemahaman Good Governance, Gaya Kepemimpinan dan Budaya Organisasi Terhadap Kinerja Auditor. SNA X Makasar. AMKP-2. 